resources are limited. The work highlights the importance of choosing wall heat transfer model and the effect in predicting performance characteristics of the model. Each wall heat transfer model is applied on the geometry with the same mesh upon performing a grid independency test [8]. The work can act as a reference for simulation performed across the globe for compression ignition diesel engine. The simulation results are compared with the experimental data. The experimental data are taken from reference of a standard turbocharged 130PS 5.675 L diesel engine (Table 1).

\subsection{Engine specifications}

The analysis is done at operating point, i.e. $2200 \mathrm{rpm}$, $547 \mathrm{Nm}$ torque, and at full load condition. The parameters are kept constant throughout the study both physical and chemical, and a comparative study is presented between three wall heat transfer models. As observed in the study with different wall heat transfers model used for compression ignition engine simulation, all fall in permissible error range, but at the same time we need to check the level of accuracy of each of them for a precise and accurate study; having an idea of the model to be used also saves the computational time. Each wall heat transfer model as is having a specific mathematical model implies different computation time. For example, Han and Reitz heat transfer model takes into account the dynamic density variation, and hence, the computation time increases as the validation for boundary condition increases in parallel. Our purpose is to validate wall heat transfer model for a compression ignition engine having performance characteristics as the benchmark.

\section{Modelling approach}

The modelling is done on a standard CFD in-cylinder combustion software having all the three wall heat transfer schemes with a rich library for turbulence model in which RNG $k-\varepsilon$ is chosen for study. The solution is obtained from the set of governing equations, law of conservation of mass, momentum, energy and species in

Table 1 Engine specification

\begin{tabular}{|c|c|}
\hline Engine displacement & $5675 \mathrm{cc}$ \\
\hline Rated power & 134.1bhp@2400 rpm \\
\hline Number of cylinders & 6 \\
\hline Type & Turbocharged \\
\hline Operating fuel & Diesel \\
\hline Rated torque & 490 Nm 1400-1800 rpm \\
\hline
\end{tabular}

SN Applied Sciences

a SPRINGER NATURE journal a three-dimensional in-cylinder in a CRDI diesel engine [9-11]

The turbulence modelling approach picked here is RNG $\mathrm{k}-\varepsilon$. The RNG model was developed using renormalisation group (RNG) methods by Yakhot et al. to renormalise the Navier-Stokes equations, to account for the effects of smaller scales of motion. In the standard k-epsilon model, the eddy viscosity is determined from a single turbulence length scale, so the calculated turbulent diffusion is that which occurs only at the specified scale, whereas in reality all scales of motion will contribute to the turbulent diffusion. The RNG approach, which is a mathematical technique that can be used to derive a turbulence model similar to the k-epsilon, results in a modified form of the epsilon equation which attempts to account for the different scales of motion through changes to the production term [12-15].

The combustion modelling is done on a standard reduced Engineering Research Center-Mechanism. The Engine Research Center had developed reaction mechanism of $\mathrm{n}$-heptane to simulate diesel fuel chemistry. The method used for mechanism development is a combination of SENKIN, XSENKPLOT and genetic algorithm. The mechanism can be used efficiently for multi-dimensional engine CFD modelling of diesel engines.

The meshing used is adaptive mesh refinement. The meshing technique basically works on the immerse boundary condition and eliminates the general problem of predefined-mesh quantification which cannot be dynamic as per real-time solution generated. The maximum cell counts are restricted here to 15 millions cells after a grid enhancement testing validation (Fig. 1).

Fuel species used for study is diesel (in liquid phase) and $\mathrm{n}$-heptane- $\mathrm{C} 7 \mathrm{H} 16$ (in gas phase after evaporation) as full kinetic dual fuel model is too complex and data information availability is also limited, so $n$-heptane is used as fuel surrogate for primary fuel in gas phase. Flow, thermal and turbulence model is Reynolds-averaged Navier-Stokes model (RNG k- $\dot{\varepsilon}$ ) for continuity, momentum and energy equations. Spray break model is based on Lagrangian transport equations, with KHRT droplet breakup and NTC-collision approach. Boiling-evaporation model adapted is Forssling evaporation model having spray wall interaction model as rebound and slide $[16,17]$. Equation of state is Redwich Kwong which is an empirical, algebraic equation that relates temperature, pressure and volume of gases. Solver parameter used for pressure velocity coupling is Rhie-Chow scheme, which is mostly applied with the aim of improving computational efficiency and speeding the coupling process especially where non-Cartesian meshing is done. 


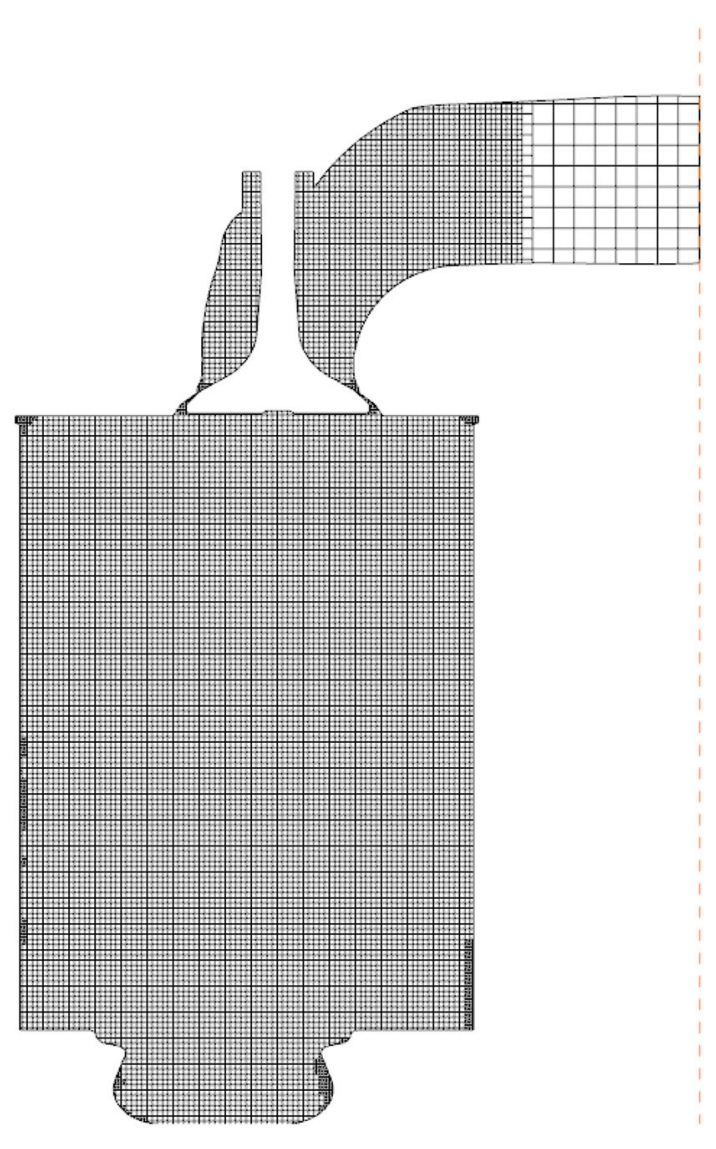

Fig. 1 AMR at a certain instance

\section{Experimental setup}

The experiment for plotting performance characteristics is performed in a standard industrial test bench under industry standard condition whose schematic diagram is presented here. The experimental setup consists of angle encoders and pressure sensor mounted on crank pulley and cylinder top, respectively, which senses current position as angle and pressure as signals. These signals are transmitted to the processing unit/amplifiers which process it, and the pressure versus crank angle plot is displayed on the display screen. The pressure vs crank angle is recorded from the experiment which is further a reference for validation purpose of the simulation activity [18] (Fig. 2).

\section{Mathematical model}

The constants used here are: $k$ is the molecular conductivity, $K$ is the von Karman constant $(0.4187), B$ is the function given by the value of $u^{+}$when $y^{+}$is equal to $1, \operatorname{Pr}_{m}$ is the molecular Prandtl number, $\operatorname{Pr}_{t}$ is the turbulent Prandtl number, $T_{f}$ is the fluid temperature, $T_{w}$ is the wall temperature, and $u_{\tau}$ is the
1) Angle Encoder mounted on Crank pulley

2) Aperture Pressure Sensor

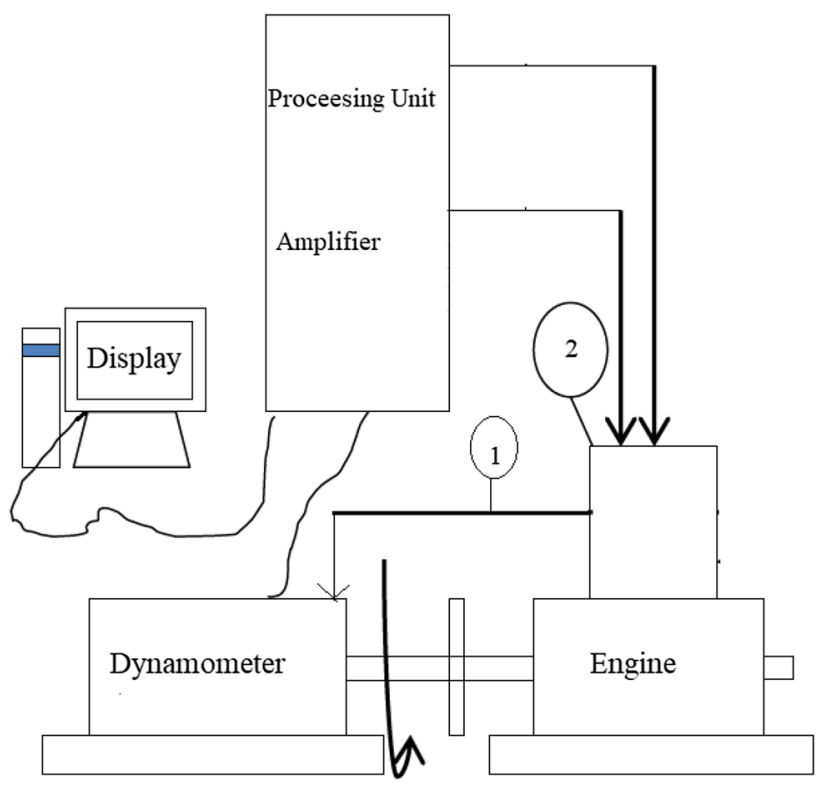

Fig. 2 Experimental setup layout

shear speed (taken from the momentum law of the wall) (Fig. 3).

The shear speed is given as

$u_{\tau}=c_{\mu}^{1 / 4} k^{1 / 2}$,

\subsection{Han and Reitz wall heat transfer model}

The Han and Reitz wall heat transfer model is given by:

$k \frac{\mathrm{d} T}{\mathrm{~d} x_{i}}= \begin{cases}\frac{\mu c_{p\left(T_{f}-T_{w)} n_{i}\right.}}{y \operatorname{Pr}_{m}} & y^{+}<11.05 \\ \frac{\rho c_{p} u \tau\left(T_{f} \ln \left(\frac{T_{f}}{T_{w}}\right) n_{i}\right.}{2.1 \ln \left(y^{+}\right)+2.513} & y^{+}>11.05\end{cases}$

The Han and Reitz model accounts for compressible effects. The Han and Reitz model also resolves the dynamic density variation effects which furthermore increases the computation time, and this kind of dynamic resolution is required where sudden density variation is taking place and has to be accounted in detail [19].

\subsection{O'Rourke and Amsden wall heat transfer model}

For the O'Rourke and Amsden model, the wall heat transfer is given by:

$k \frac{\partial T}{\partial x_{i}}=\frac{\mu_{m} C_{p} F\left(T_{f}-T w\right)}{\operatorname{Pr}_{m} y} n_{i}$ 


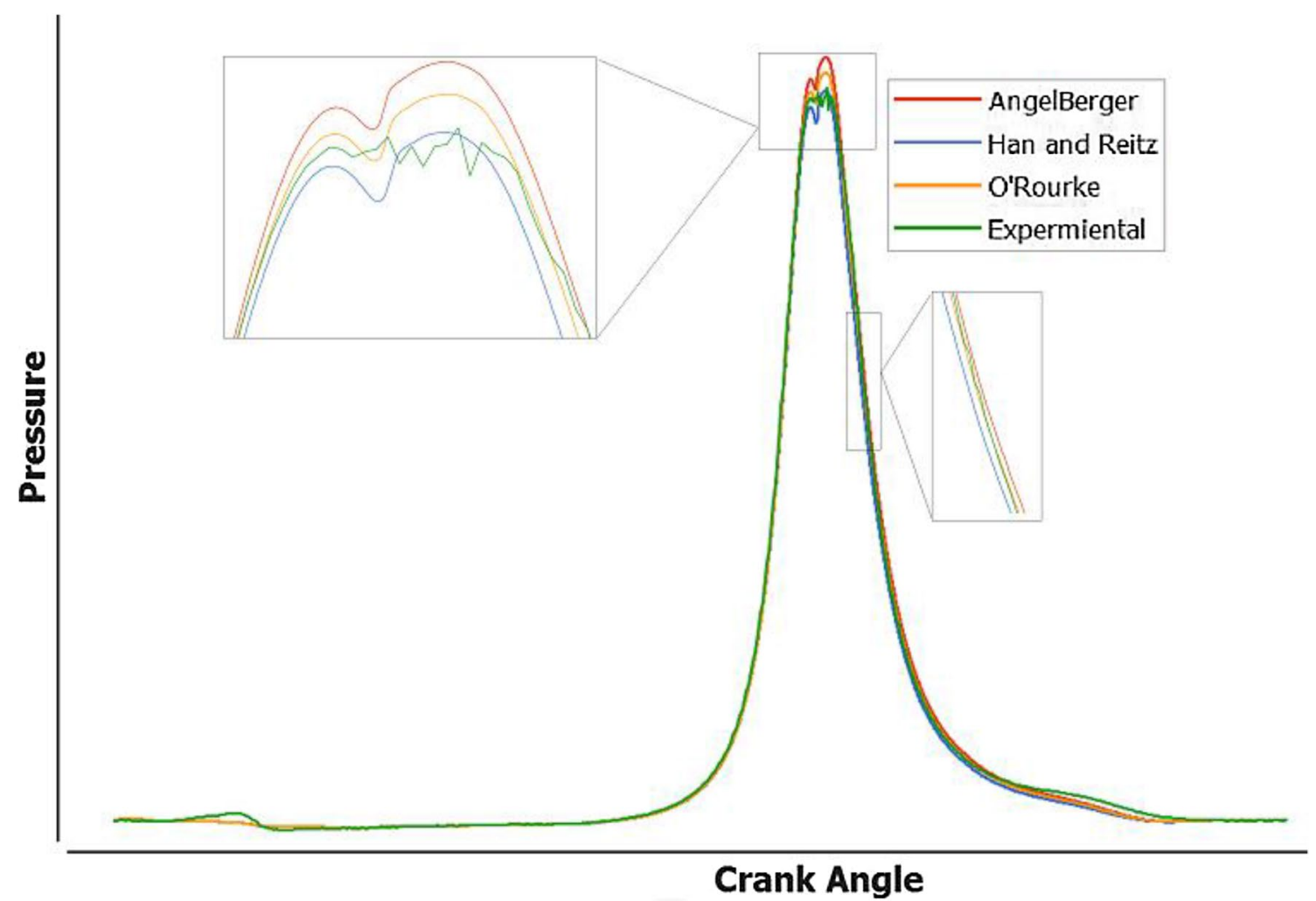

Fig. 3 Comparison of each wall heat transfer model curves pressure versus crank angle

where

$F= \begin{cases}1.0 & y^{+}<11.05 \\ \frac{\left(\frac{y^{+} \mathrm{Pr}_{m}}{\mathrm{Pr}_{t}}\right)}{\frac{1}{\kappa} \ln \left(y^{+}\right)+B+11.05\left(\frac{\mathrm{Pr}_{m}}{\mathrm{Pr}_{t}}-1\right)} & y^{+}>11.05\end{cases}$

$y^{+}=\frac{\rho \mu_{\tau} y}{u_{m}}$

The O'Rourke and Amsden wall film model predicts film transport on complex surfaces, heating and vaporisation of the film, and separation and re-entrainment of the liquid film at sharp corners it also incorporates the effects associated with spray/wall interactions-including droplet splash, film spreading due to impingement forces, and motion due to film inertia. The model is specially design in a way to perform study for IC engine, and the computational time is also relatively lesser than the other two models and hence is optimised for operation [4].

\subsection{Angelberger wall heat transfer model}

$k \frac{\mathrm{d} T}{\mathrm{~d} x_{i}}=\frac{\rho_{w} c_{p} u_{\tau} \ln \left(\frac{T_{f}}{T_{w}}\right) n_{i}}{\theta^{+}}$ where

$\theta^{+}= \begin{cases}\operatorname{Pr} y^{+} & y^{+} \leq 13.2 \\ 2.075 \ln \left(y^{+}\right)+3.9 & y^{+}>13.2\end{cases}$

The Angelberger model accounts for quasi-isothermal flow (e.g. in intake pipes or compression during engine simulations) and for non-isothermal wall flow (e.g. in the combustion chamber during combustion or in exhaust pipes). The Angelberger model consistently predicts lower wall heat fluxes than the Han and Reitz model [2].

\section{Results}

The result is plotted and pressure versus crank angle curve is compared, and further, the values of IMEP are compared and the wall heat transfer model with least error is taken for further study and analysis.

The Han and Reitz model underpredicts the indicated mean effective pressure value which is above the permissible limits as of more than $10 \%$ error. The O'Rourke Wall heat transfer model underpredicts the result by $2 \%$ which is nearly close to the actual value while the Angelberger wall heat transfer model overpredicts the value by $4 \%$ which is not acceptable for further study. Also as we 
observe the apparent integrated heat release rate plotted from start of injection to exhaust valve opening, the mean curve follows the path of simulation curve obtained from O'Rourke model. So O'Rourke heat transfer model gives a close prediction for performance parameter (Fig. 4 and Table 2).

\section{Discussion}

The boundary conditions and the precise modelling enable the O'Rourke model for predicting the performance characteristics curve very close to that of the experimental result. On the other hand, Han and Reitz account for the compressible effects; in this particular model, there is a gap in predicting the result as compared to the O'Rourke model, whereas Angelberger is suitable for modelling the quasi-isothermal case where the gap between the film temperature and wall temperature is relatively lower as suggested by its physics and boundary conditions.

O'Rourke and Amsden wall heat transfer model predicts film transport on complex surfaces, heating and vaporisation of the film, and separation and re-entrainment of the liquid film at sharp corners. Vaporisation of the films is due to differences between the fuel vapour mass fraction
Table 2 Comparison between performance parameter with each wall heat transfer model

\begin{tabular}{llll}
\hline Wall heat transfer model & Han and Reitz & O'Rourke & Angelberger \\
\hline Rotation per minute & 2200 & 2200 & 2200 \\
$\begin{array}{l}\text { Indicated mean effective } \\
\text { pressure (bar) }\end{array}$ & 13.05 & 14.28 & 15.20 \\
\begin{tabular}{l} 
\%Error \\
\hline
\end{tabular} & 10.54 & 2.10 & -4.20 \\
\hline
\end{tabular}

in the bulk gas above the films and the vapour mass fraction at the surface of the film determined by its surface temperature. The film surface temperature is determined implicitly by a wall film temperature equation. The parameters such as mass, momentum and energy are also well predicted by the wall functions for turbulent boundary layers near the films which are in vaporising state.

\section{Conclusion}

Since the O'Rourke wall heat transfer is giving the most optimised result both from the point of 'accuracy' as illustrated and computational feasibility as the computation time for $O^{\prime}$ Rourke being $X$ is $1.25 X$ and $1.75 X$ for

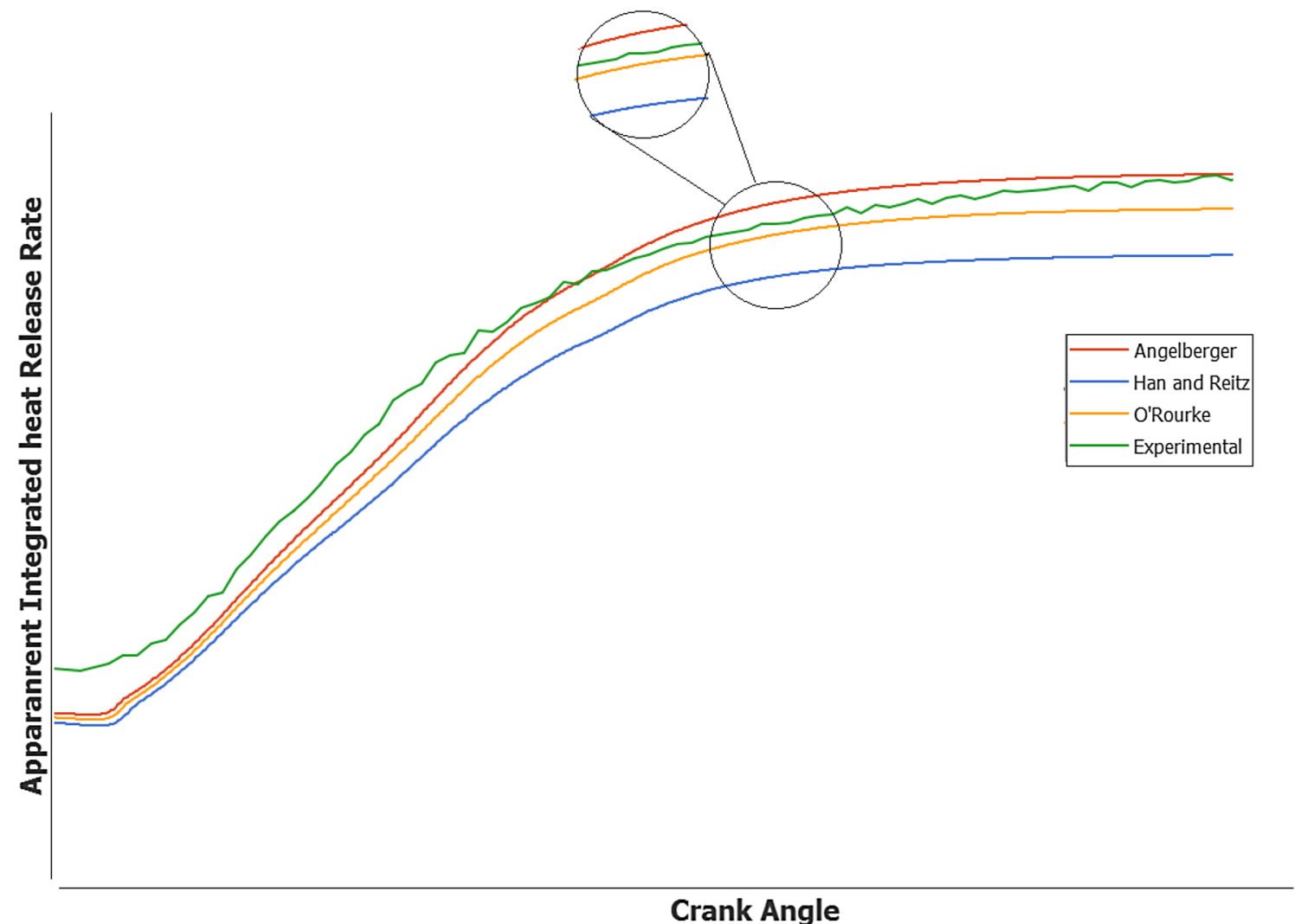

Fig. 4 Comparison of each wall heat transfer model for apparent integrated heat release rate 
Angelberger and Han and Reitz, respectively. O'Rourke and Amsden wall heat transfer model is observed to be suitable for study for in-cylinder CFD combustion study for mapping performance parameter of a standard diesel engine.

\section{Compliance with ethical standards}

Conflict of interest The authors declare that they have no conflict of interest.

\section{References}

1. Šarić S, Basara B et al. (2015) Advanced near-wall heat transfer modelling for in-cylinder flows. In: International multidimensional engine modeling user's group meeting at the SAE congress, Detroit, MI, 20 April 2015

2. Angelberger C, Poinsot T, Delhaye B (1997) Diagnostics and modeling in $\mathrm{SI}$ engines improving near-wall combustion and wall heat transfer modeling in si engine computations. SAE technical papers. https://doi.org/10.4271/972881

3. O'Rourke P, Amsden A (1996) A particle numerical model for wall film dynamics in port-injected engines. SAE technical paper 961961. https://doi.org/10.4271/961961

4. O'Rourke P, Amsden A (2000) A spray/wall interaction submodel for the KIVA-3 wall film model. SAE technical paper 2000-01-0271

5. Sanjin Saruc et al. (2015) A hybrid wall heat transfer model for IC engine simulations. SAE teachnical papers

6. Sircar A et al. (2017) An assessment of CFD-based wall heat transfer models in piston engines. In: 10th U. S. national combustion meeting

7. Piazzullo D, Costa M, Allocca L, Montanaro A et al (2017) A 3D CFD simulation of GDI sprays accounting for heat transfer effects on wallfilm formation. SAE Int J Engines 10(4):2166-2175

8. Sideri M, Berton A, D'Orrico F (2017) Assessment of the wall heat transfer in 3D-CFD in-cylinder simulations of high performance diesel engines. Energy Procedia 126:963-970

9. Lakshminarayanan PA, Aghav YV (2010) Modelling diesel combustion. Springer Science and Public Media, Berlin
10. Ahmadi-Befrui B, Uchil N, Gosman AD, Issa RI (1996) Modeling and simulation of thin liquid films formed by spray-wall interaction. SAE paper 960627

11. Plengsa-ard $C$, Kaewbumrung $M$ (2018) CFD modelling wall heat transfer inside a combustion chamber using ANSYS forte. In: IOP conference series: materials science and engineering. vol 297, p 012036. https://doi.org/10.1088/1757-899x/297/1/012036

12. Ihme $\mathrm{M}$ et al. (2016) Non-equilibrium wall-modeling for largeeddy simulation of internal combustion engines. In: THIESEL 2016 conference on thermo-and fluid dynamic processes in direct injection engines

13. Seo J, Lee JS, Choi KH, Kim HY, Yoon SS (2013) Numerical investigation of the combustion characteristics and wall impingement with dependence on split-injection strategies from a gasoline direct-injection spark ignition engine. Proc Inst Mech Eng Part D J Automob Eng 227(11):1518-1535

14. Costa TJ, Nickerson M, Littera D, Martins J, Shkolnik A, Shkolnik N, Brito $F$ (2016) Measurement and prediction of heat transfer losses on the XMv3 rotary engine. SAE Int J Engines 9(4):2368-2380

15. Zhang Y, Liu Z, Zuo Q, Xiao B, Sun S, Fu J (2018) Heat transfer model for high power density internal combustion engine based on fluid-solid coupling model. Zhongnan Daxue Xuebao (Ziran Kexue Ban)/J Central South Univ (Sci Technol) 49:23302336. https://doi.org/10.11817/j.issn.1672-7207.2018.09.028

16. Zhang Y (2014) Development of a new spray/wall interaction model for diesel spray under $\mathrm{PCCl}$-engine relevant conditions. At Spray 24(1):41-80. https://doi.org/10.1615/atomizspr.20130 08287

17. Jia M, Gingrich E, Wang H, Li Y, Ghandhi JB, Reitz RD (2016) Effect of combustion regime on in-cylinder heat transfer in internal combustion engines. Int J Engine Res 17(3):331-346. https:// doi.org/10.1177/1468087415575647

18. Gokul Raj CR et al (2018) Combustion and emission characteristics of a direct injection diesel engine at various EGR conditions-a numerical and experimental study. Eur J Adv Eng Technol 5(1):35-42

19. Deng P, Han Z, Reitz RD (2016) Modeling heat transfer in spray impingement under direct-injection engine conditions. Proc Inst Mech Eng Part D J Automob Eng 230(7):885-898

Publisher's Note Springer Nature remains neutral with regard to jurisdictional claims in published maps and institutional affiliations. 